\title{
Academic Students' Attitudes toward Students with Learning Disabilities
}

\author{
Ayala Gonen ${ }^{1}$, Keren Grinberg ${ }^{2}$ \\ ${ }^{1} \mathrm{PhD}$. RN, Nursing Department, School of Social and Community Sciences, Ruppin Academic Center, Emeq-Hefer, \\ Israel \\ ${ }^{2} \mathrm{PhD}$. Candidate, RN, Nursing Department, School of Social and Community Sciences, Ruppin Academic Center, \\ Emeq-Hefer, Israel \\ Correspondence: Ayala Gonen, Ruppin Academic Center, Emeq-Hefer, Israel.
}

Received: July 4, $2016 \quad$ Accepted: July 27, $2016 \quad$ Online Published: August 31, 2016

doi:10.11114/jets.v4i9.1709 URL: http://dx.doi.org/10.11114/jets.v4i9.1709

\begin{abstract}
Background: Learning disabilities (LD) are lifelong disabilities that affect all facets of a person's life. Aim: Identifying the relationship between academic students' attitudes toward learning disability, self-image, and selected factors. Methods: A questionnaire was distributed to 213 students from an academic center in Israel. Two different scales were used: (1) Students' Attitudes scale toward students with learning disability; (2) Students' Self-image scale. Results: 1. the student attitudes scale were found to be relatively high. 2. A significant positive relationship was found between students' attitudes and their self-image. 3. More positive attitudes were found among those students who have friend with learning disabilities. Conclusion: The results of this study indicate the necessity of reinforce students self-image and to encourage the students to socialize with students who have LD, in order to strengthen the positive and favorable attitudes of students at the academy, which will positively have impact on the success of the integration of students with learning disabilities into the community and society.
\end{abstract}

Keywords: academic students, attitudes, learning disabilities, self-image

\section{Introduction}

Learning disabilities (LD) are lifelong disabilities that affect a person's life, and are characterized by a significant difference in a person's achievements. A student with a learning disability may show one or more of the following characteristics: Difficulty in reading, writing, written expression, spelling, math calculations, or math reasoning, or having memory and perception problems, speech and language disorders, and being easily distracted and difficulty while having to sit still.

Over the years, society's attitude towards those with learning disabilities was based upon its frequently changing expectations and social consciousness (Waldeman et al., 1999; Coyle et al., 2004; Zhao, 2012). When students having LD fail to acquire adequate literacy skills, it may lead them to experience unsatisfactory academic outcomes (Hitchcock, et al., 2004; Kamil, 2003).

The number of college students in United States that were self-identified as having learning disabilities has risen from $0.6 \%$ to $12.2 \%$ (White et al., 1980). The increasing numbers of students with LD comprise the largest single group of college students with disabilities receiving university services (Bulgren et al., 2013). These services include classroom accommodations, personal counseling, and academic support services. In Israel, the number of students with LD are increasing also (Greenbarger \& Leyser, 2008), and the numbers are approximately $10 \%$ of the students. This situation raises some questions like: what are the attitudes of students with no LD, toward students who have LD?

\subsection{Attitude to Behavior}

Attitude to behavior relates to the degree of an individual's positive or negative assessment of behavior/planned behavior. Attitudes are an important concept in human behavior and it is used to explain various human behaviors, primarily social behavior. It is possible to understand the basis of human behavior by measuring beliefs that are the basis for attitudes (Ajzen, \& Fishbein, 1980), and the attitudes' information can be valuable in designing effective programs for behavioral intervention. The classical ABC Model claim that there are three main attitudes' components that have relationship between themselves: Affect, Behavior, and Cognition (Philipchalk,1995 ; Eagly \& Chaiken, 1993). The connection between them is significant; therefore, creating a change in one, it will have a direct effect on the other. 
The relationship between the attitudes and the behavior can better be understood if we accept the assumption that human beings are rational enough to take into account any implication that may result from their actions. A person learns from experience how the social environment reacts to his/her reactions and behaves accordingly. That is why the issue of understanding the student's behavior toward another student is an important area that arouses interest among many researchers.

It was interesting to find out that most of the studies focus on the educators attitudes which report negative attitudes of faculty members toward students with LD (Mastropieri et al., 2008), while other studies reported a positive attitudes ( Scott \& Gredd, 2000; Vogel et al., 2006).

To our knowledge, very little is known about students' attitudes toward students with Learning Disabilities. One study examined the attitudes of dental students comparing to social policy students towards students with learning disabilities in order to identify whether attitudinal differences exist. It was found that dental undergraduates' students were having less favorable attitudes towards those with learning disability (Coyle et al., 2004).

\subsection{Self-image}

Self-image is the position of the person about himself, formulated by his experiences of successes and failures, according to the way of his perceptions and explanations (Kaniel, 2006). Therefore, self-image is a very subjective perception.

Among the many aspects of the personality, the self-image is the individual's personal belief structure. Individuals with high self-esteem have an internal control orientation that has a greater probability of conforming to the instrumental ideology of conventional society and rejects behaviors that might jeopardize such an outlook on society or that could be problematic to themselves or society (Ellis, 2016). Self-image may be affected by the students' talents and their perceptions of the environment. It can be noted that the student sees himself as others see him, and he tends to act in accordance with the expectations of the characters with whom he comes in contact (Sant et al., 2016).

High Self-Image has a significant effect on the student ability to learn and it plays an important role in the students behavior, including having effect on their learning and social motivation. Low Self-image can affect students' abilities to make and keep friends which also can have an impact on educational achievement due to behavioral problems (Lyons, 2012).

One way to carry out a research on self-image is by the classic self-image questionnaire that was written by Rosenberg (1965), and it is very popular among researchers. Rosenberg' questionnaire is very common due to its simplicity and its direct questions about feelings.

\subsection{Students' Area of Specialization}

Virginia Henderson (1964), one of the theoretician of the nursing profession, claims that the role of a nurse is to assist the individual, sick or healthy, and to contribute to his health. Nursing is a profession based on giving, in which the nurse feel that she should be accessible and ready to help and support the patient, and help him to achieve a state of well-being. Studies show that the main causes for choosing the nursing profession are sense of giving, sense of mission, and willing to service (Eley et al.,2012; Price et al., 2013) as it can be called as altruistic feeling and sense of compassion. These characteristics are very similar to those students who had chosen the other caring profession like behavioral science. The educational experiences contribute to the favorable attitudes of the behavioral and nursing department students, more than students from industrial department (Kohli et al., 2015). The authors believe that in contrast, the industrial science students, are not supposed to have such feeling due to their area of specialization, so their attitudes toward LD students might be more negative.

\subsection{Aim of This Research}

The research's main goal is to investigate preferred factors related to students' attitudes toward students with learning disabilities. The study will also include number of variables such as: Students' self-image, academic field of the student' study, gender ethnicity, level of religiosity and factors of personal experience with LD such as having a friend with LD. This information will give us insights about the students' behavior regarding cooperation with LD students, and will point out the characteristics of the relationship between their attitudes and some personal and professional factors .

\subsection{Research Hypotheses}

1. Students from behavioral and nursing department will have more positive attitudes toward students with LD, than students from industrial department.

2. Students with high self-image, will have more positive attitudes towards students with LD. 
3. Differences will be found between background factors like gender, ethnicity and Level of religiosity and students' attitudes toward LD.

4. Students, who have student's friend with LD, will have more positive attitudes toward LD.

\subsection{The Importance of the Research}

The findings of this study contribute to expanding the body of knowledge for students' attitudes toward LD, in the context of understanding the human factor involved in this issue. Analysis of the results can serve as a knowledge base to build a proper and adaptive program for proper integration of LD students in the academy.

\section{Methods}

The study is a quantity research, in which questionnaires were used in order to find out more about the relationship between students attitudes toward other students diagnosed with LD, students self-image and preferred variables. The data was collected in 2015. Participation of the students was voluntary and the data was treated in confidence. The research tool was a written and online survey. The questionnaire was accompanied by an introductory letter including information about the purpose of the study, assurance of confidentiality and each participant was asked to sign his consent. Out of the 300 questionnaires, 213 were returned (total response rate $71 \%$ ).

\subsection{Ethical Consideration}

The research was approved by the Ethics Committee of the Academic Center. The participants were asked to complete a questionnaire on a voluntary basis and their rights to anonymity and confidentiality were ensured.

\subsection{Measures}

Research tool: The survey instrument was organized into three groups of questions:

A. Background questions such as: gender, ethnicity, level of religiosity, and Field of study (see table 1).

Table 1. Background Data

\begin{tabular}{llll}
\hline & Variable & N & \% \\
\hline Gender & Male & 52 & 24.9 \\
& Female & 157 & 75.1 \\
Religious & Jewish & 169 & 79.7 \\
& Arabs & 35 & 16.5 \\
Religiosity & Secular & 120 & 57.4 \\
& Religious & 83 & 39.7 \\
Field of study & Industrial and Management & 23 & 10.8 \\
& Behavioral Sciences & 107 & 50.2 \\
& nursing & 76 & 36.6 \\
Friend with LD & Yes & 166 & 78.3 \\
& No & 45 & 21.2 \\
\hline
\end{tabular}

B. Personality variables such as: Attitudes toward students with LD and students' self-image. The scale for measuring Attitudes toward learning disability was adapted by the author and consisted of 3 groups of questions that are based on the ABC Model that includes: Affect, Behavior, and Cognition which are three components that have relationship between them (Eagly \& Chaiken, 1993). The connection between these three elements is significant, and a change in one of them, directly affects the others. Each group included 7 question in the 5-point Likert scale and the inner consistency (Cronbach's alphas) of whole scale (21 questions) was $\alpha=0.69$. Each group had also a good inner consistency (Cronbach's alpha): Emotional: $\alpha=0.64$, Cognitional: $\alpha=0.64$, Behavioral: $\alpha=0.72$.

Students' self-image scale was taken from the classic Rosenberg's scale (1965). The scale consisted of 10 questions in the 5-point Likert scale and the inner consistency (Cronbach's alphas) of whole scale was: $\alpha=0.87$.

C. Personal experience with LD: The question that was asked was whether the student has a friend with LD.

\subsection{Data Analysis}

The first hypothesis dealt with differences in attitudes between students studying nursing and behavioral sciences comparing to students studying engineering. Independent T-test was conducted. The second hypothesis dealt with differences in attitudes among students with low or high self-image. Hierarchical regression was performed. The third hypothesis dealt with differences in attitudes among gender, ethnicity and 3 stages of religious levels. Three ways Anova test was performed. The forth research hypothesis referred to the question will we find differences between the students' attitudes toward LD and factors of personal experience with LD. we performed a stepwise hierarchical regression 


\section{Results}

\subsection{The First Research Hypothesis}

The first Research hypothesis was Students from behavioral and nursing department will have more positive attitudes toward students with LD, then students from industrial department.

Positive attitudes toward students with Learning Disability were higher among nursing students $(\mathrm{M}=4.671, \mathrm{SD}=1.23)$ compare with industrial department students $(\mathrm{M}=3.216, \mathrm{SD}=0.650)(\mathrm{t}=2.13, \mathrm{p}=0.04)$. On the Likert scale of $1-5,46.8 \%$ of the participants indicated the 4 scale. In addition, we compared nursing and behavioral sciences students to students studying engineering. T-test was conducted and the hypothesis was not confirmed and no statistically significant difference appeared.

\subsection{The Second Research Hypothesis}

The second research hypothesis referred to the question; will we find differences between the students' attitudes toward LD -and their self-image ?Or to be more accurate, to what extent students' higher self-image affects their attitudes towards students with LD. We found that the median of self-image variable was 4.2 , i.e. $50 \%$ of the students have a self-image of up to, 4.2 (on 1-5 scale), and 50\% are above 4.2. The average is 4.08. 110 students were defined as having low self-image and 94 had high self-image.

A significant positive relationship was found between the students' self-image and their attitudes toward students with learning disability, the higher student's self-image, the higher is his attitudes toward students with learning disability (see table 2).

Table 2. Correlations between $\mathrm{ABC}$ attitudes components and Self-image

\begin{tabular}{|c|c|c|c|}
\hline Self image & \multicolumn{2}{|c|}{ ABC attitudes components } & \\
\hline $.300^{* *}$ & \multirow{3}{*}{$\begin{array}{c}\text { Pearson Correlation } \\
\text { Sig. (2-tailed) } \\
\text { N }\end{array}$} & \multirow[t]{3}{*}{ Cognitive } & \multirow[t]{3}{*}{1} \\
\hline .000 & & & \\
\hline 204 & & & \\
\hline $.275^{* *}$ & \multirow{3}{*}{$\begin{array}{c}\text { Pearson Correlation } \\
\text { Sig. (2-tailed) } \\
\text { N }\end{array}$} & \multirow[t]{3}{*}{ Emotion } & \multirow[t]{3}{*}{2} \\
\hline .000 & & & \\
\hline 204 & & & \\
\hline $.217^{* *}$ & \multirow{3}{*}{$\begin{array}{c}\text { Pearson Correlation } \\
\text { Sig. (2-tailed) } \\
\text { N }\end{array}$} & \multirow[t]{3}{*}{ Behavior } & \multirow[t]{3}{*}{3} \\
\hline .002 & & & \\
\hline 204 & & & \\
\hline
\end{tabular}

**. Correlation is significant at the 0.01 level (2-tailed).

In addition, a hierarchical regression was assessed. In the first step, all independent variables were entered, except for self-image. In the second step, self-image was added and this resulted in an additional $8.6 \%$ of the attitudes' explained variance. Furthermore, the variable of self-image was found to have a significant particularly contribution.

\subsection{The Third Hypothesis}

The third hypothesis was: Will we find differences between the students' attitudes toward LD and background factors like gender, ethnicity and Level of religiosity? Three ways Anova tests was performed, looking for analyzing of the variants. The differences were not statistically significant and the hypothesis was not supported.

\subsection{The Forth Research Hypothesis}

The forth research hypothesis referred to the question: Will we find differences between the students' attitudes toward LD and personal experience with LD, such as having a student friend with LD .

$\mathrm{T}$ test for independent differences found that the attitudes of students who had friend with learning were significantly higher than those who do not. $(M=3.91, M=4.08$,). Furthermore, the difference was found to be statistically significant $(t$ $(202)=2.44, p=.016)$. This gap reflects a difference of 0.39 standard deviation [0.34, 0.45] CI 95\%. Accordingly, we can point out that students, who have friends with $\mathrm{LD}$, were found to have more positive attitudes, compared to students that do not have friend with LD .

It is important to note that when we performed an hierarchical regression to predict attitudes toward students with LD and having a friend with learning disability, we found that the model in general was not statistically significant $(F(2,196)=$ 
$2.83, \mathrm{p}=.061)$. However, it was found that the unique contribution of having a friend with $\mathrm{LD}$, is statistically significant $(t$ $(196)=-2.38, p=0.018, r=-.17)$, thus, our hypothesis was confirmed.

\section{Discussion}

Positive attitudes toward students with Learning Disability were found among the students from three different departments: Nursing, behavior and Engineering. $46.8 \%$ of the participants indicated 4 (out of the Likert scale of 1-5). It is a good sign and it proves that the attitudes toward student with LD are improving and according to it, students with LD are more tolerated by other students. There is evidence that attitudes toward disability are improving in other countries like Ireland and worldwide (Hannon, 2007) as it was also proven in a complementary study of 6000 US students was undertaken to assess differences in youth attitudes between the two nations (Norins-Bardon et al, 2005). North American students were more willing to interact with peers with disabilities than their Japanese counterparts and they had better perceptions of the competencies of students with intellectual disabilities reflecting their higher exposure to students with intellectual disabilities.

Two main results were prominent in this study: A. Significant positive correlation was found between the students' attitudes toward LD-and their self-image. Furthermore, the variable of self-image was found to have a significant contribution for understanding the students' attitudes toward LD. B. The attitudes of students who have friends with LD are significantly higher, than those who do not have friends with LD.

Self-image is a strong motivating factor and it is quite clear that students' personality characteristic like self-image is considered as important factor in considering ways to promote the integration of the disable students in the academic surrounding. Rentzsch, Schröder-Abé, \& Schütz, (2015) found that students with low academic self-image may exhibit hostile tendencies because of feelings of envy, especially in highly competitive contexts. That is why it is so important to find ways to promote the students self-image.

It is entirely obvious that students' personality characteristics like personal experience with other students LD should be considered as important factors in finding ways to advance the integration of LD students in the academy surrounding. A clear relationship between attitudes and personal experience of disability was found in both the 2001 and 2006 national surveys in the Republic of Ireland as well as in many other studies worldwide (Hannon, 2007).

In summary, our main aim was to identify the relationship between student's attitudes toward LD, self-image, and selected factors. Figure no 1 demonstrate the importance of 2 major variants that were found when we looked for reasons for having positive attitudes toward LD: Having high Self-Image and having a friend with LD.

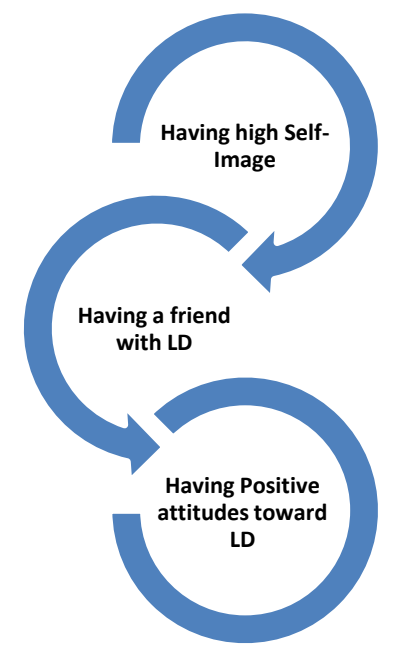

Figure 1. Research model

We did not find correlation between the students' attitudes toward LD -and the specific academic field of the student' study. We believe that Behavior and Nursing Sciences are two fields that are related to human behavior and accordingly. It was hypothetical that students that choose to learn such areas will have more positive attitudes toward students with LD, then students who study Engineering science. Surprisingly, this hypothesis was not proven. It can be explained by two reasons: Only 23 students (10.8\%) from the participants came from the Engineering department, so it might be an inaccurate sample. The whole score for the students' attitudes toward students having LD was relatively high (46.8\% of the participants indicated the 4 scale, out of 1-5 scale). It might be also explained by the fact that in the researched academic center there is a very active students' support department that its unique task is to provide the students with disability a complete sense of integration into academic life. 
No differences were found between the students' attitudes toward LD and background factors like gender, ethnicity and Level of religiosity. Ajzen \& Fischbein in their book Understanding Attitudes and Predicting Social Behavior (1980) claim that beliefs are the determinant of the attitudes. These beliefs probably come from other factors like culture, environment and personal parameters that were not researched in this study and it is possible that a correlation will be found when performing a larger study concluding more relevant variables. Support for those claims is arising from Oliver's model of disability (1990) which described social, cultural and environmental barriers that lead to the discrimination of those with a disability. Consequently, a positive change in attitude would lead to equal opportunity and improved the LD student's quality of life.

\section{Research Limitations}

The current study was performed in one academic center. The authors recommend that the policy makers will research this issue more profoundly in order to find ways to raise the students' positive attitude toward other students with learning disability because it is the basic for an equal society.

It was a convenient study and the sample was small, especially in checking the differences of the background factors like gender, ethnicity and Level of religiosity.

We had also some difficulties in looking for prior research studies on the topic.

\section{Conclusion}

The study's results indicate that student' personality characteristics like self-image and students personal experience with other students LD, should be considered as important factors in looking for ways to promote the integration of the disable students in the academy surrounding.

The results of this study specify two main issues: the necessity to reinforce students' self-image and to encourage the students to have friends with LD, all this, in order to strengthen the positive and favorable attitudes of students at the academy, which will impact directly and positively on the integration of students with LD into the community. As a result, the benefits for the undergraduate students will be a positive change in their ability to develop a meaningful understanding of students with LD, a point of view that will make our world much better.

\section{Acknowledgements}

We are grateful to the students who participated in this study.

\section{Conflict of Interest}

There are no possible conflicts of interest in the manuscript including financial, consultancy, institutional or other relationships that might lead to bias or a conflict of interest.

\section{References}

Ajzen, I., \& Fishbein, M. (1980). Understanding attitudes and predicting social behavior. Prentice Hall, inc. NJ

Bulgren, J. A., Graner, P. S., \& Deshler, D. D. (2013). Literacy Challenges and Opportunities for Students with Learning Disabilities in Social Studies and History. Learning Disabilities Research \& Practice, 28(1), 17-27. http://dx.doi.org/10.1111/ldrp.12003

Coyle, C., Saundersen, W., \& Freeman, R. (2004). Dental students, social policy students and learning disability: do differing attitudes exist? European Journal of Dental Education, 8, 133-139. http://dx.doi.org/10.1111/j.1600-0579.2004.00343.x

Eagly, A., \& Chaiken, S. (1993). The psychology of Attitudes. Harcourt Brace College Publishers. Florida, USA.

Eley, D., Eley, R., Bertello, M., \& Rogers-Clark, C. (2012). Why did I become a nurse? Personality traits and reasons for entering nursing. J. of Advanced Nursing, 68, 1546-1555. http://dx.doi.org/10.1111/j.1365-2648.2012.05955.x

Ellis, W. L. (2016). Risky sexual behaviors among sexually active first-year students matriculating at a historically Black college: Is a positive self-image an instigator? Social Work in Health Care, 55(2), 125-143. http://dx.doi.org/10.1080/00981389.2015.1108949

Greenbarger, L., \& Leyser, Y. (2008). Students with disabilities in teacher education colleges-attitudes of faculty members and their willingness to provide accommodations. Issues in Special Education \& Inclusion, 5-22.

Hannon, F. (2007). Literature review on attitudes towards disability. National Disability Authority.Frances Hannon Literature Review on Attitudes towards Disability

Henderson, V. (1964). The Nature of Nursing. American Journal of Nursing, 64, 62-68. http://dx.doi.org/10.2307/3419278 
Hitchcock, C. H., Prater, M. A., \& Dowrick, P. W. (2004). Reading comprehension and fluency: examining the effects of tutoring and video self-modeling on first grade students with reading difficulties. Learning Disabilities Quarterly, 27, 89-103. http://dx.doi.org/10.2307/1593644

Kaniel, S. (2006). Teaching thinking. Tel Aviv: Ramot, Tel Aviv University Press (in Hebrew).

Kohli, N., Sullivan, L., Sadeh, S., \& Zopluoglu, C. (2015). Longitudinal mathematics development of students with learning disabilities and students without disabilities: A comparison of linear, quadratic, and piecewise linear mixed effects models. Journal of School Psychology, 53(2), 105-120. http://dx.doi.org/10.1016/j.jsp.2014.12.002

Lyons, A. (2012). Self-esteem and learning disabilities. Retrieved from http://www.ldail.org/esteem.cfm

Mastropieri, M. A., Okolo, C. M., \& Scruggs, T. E. (2008). Science and social studies for students with disabilities. Focus on Exceptional Children, 41(2), 1-32.

Norins-Bardon, \& Matsumoto, S. (2005). Paper US students attitudes to students with intellectual disabilities at the Global Youth Summit, Nagano, Japan, February 2005 available at www.specialolympics.org.

Oliver, M. (1990). The politics of disablement. Basingstoke: Macmillan. http://dx.doi.org/10.1007/978-1-349-20895-1

Phillipchalk, R. P. (1995) Invitation to social psychology. Harcourt Brace College Publishers. Canada.

Price, S. L., McGillis, H. L., Angus, J. E., \& Peter, E. (2013). Choosing nursing as a career: a narrative analysis of Millennial nurses' career choice of virtue. Nursing Inquiry, 20, 305-316. http://dx.doi.org/10.1111/nin.12027

Rentzsch, K., Schröder-Abé, M., \& Schütz, A. (2015). Envy mediates the relation between low academic self-esteem and hostile tendencies. Journal of Research in Personality, 58, 143-153. http://dx.doi.org/10.1016/j.jrp.2015.08.001

Rosenberg, M. (1965). Society and the adolescent self-image (p. 326). Princeton, NJ: Princeton University Press. http://dx.doi.org/10.1515/9781400876136

Sant, E., Davies, I., \& Santisteban, A. (2016). Citizenship and Identity: The Self-Image of Secondary School Students in England and Catalonia. British Journal of Educational Studies, 64(2), 235-260. http://dx.doi.org/10.1080/00071005.2015.1070789

Scott, S. S., \& Gregg, N. (2000). Meting the evolving education needs of faculty on providing access for college students with learning disabilities. Journal of Learning Disabilities, 33(2), 158-167. http://dx.doi.org/10.1177/002221940003300204

Vogel, S. A., Leyser, Y., Burgstharler, S., Sligar, S. R., \& Zecker, S. G. (2006). Faculty knowledge and practices regarding students with disabilities in three constracting institutions of higher education. Journal of Postsecondary Education and Disability, 18(2), 109-123.

Waldeman, H., Swerdloff, M., \& Perlamn, S. (1999). Children with mental retardation: stigma and stereotype images are hard to change. Journal of Dentistry for Children, 66, 343-347.

White, W. J., Schumaker, J. B., Warner, M. M., Alley, G. R., \& Deshler, D. D. (1980). An epidemiological study of learning disabled adolescents in secondary schools: Achievement and ability, socioeconomic status, and school experiences, 1-56.

Zhao, Y. (2012). World class learners: Educating creative and entrepreneurial students. Thousand Oaks: Corwin press.

\section{$(\mathrm{Cc}) \mathrm{BY}$}

This work is licensed under a Creative Commons Attribution 3.0 License. 